\title{
Dynamic Analysis of Two-lane Skewed Bridge and High-speed Train System
}

\author{
Meysam Jahangiri1* ${ }^{*}$ Jabar-Ali Zakeri ${ }^{1}$ \\ 1 Faculty of Railway Engineering, \\ Iran University of Science and Technology, \\ Narmak, Teheran, Iran \\ *Corresponding author, e-mail: m_jahangiri@rail.iusc.ac.ir
}

Received: 14 September 2018, Accepted: 29 April 2019, Published online: 28 May 2019

\begin{abstract}
Bridges are vital in the operation of railway networks since any hindrances to their operation could suspend the flow of traffic. An important characteristic of bridges highly affecting their behavior is the skew angle. In this paper, a sensitivity analysis is performed to identify the effects of skew angle on train-track interaction for single- and double-sided crossings of a high-speed train. Comprehensive three-dimensional finite element models of the bridge and vehicle are developed, which are then calibrated using dynamic field test results. Effects of skew angle on shape modes and modal frequencies, acceleration values, and bridge displacement in various crossing speeds are studied. The results showed that if the bridge skew angle is more than $15^{\circ}$, it will affect the modal shape and frequency of the bridge. When the skew angle is less than $15^{\circ}$, the results of the bridge displacement are similar to those of the bridge with skew angle of zero. However, with the increase of the skew angle, the deformation value of the bridge decreases and the speed corresponding to the maximum displacement value also varies. Finally, the results of acceleration due to the speed and skew angle of the bridge are not the same in one-way and two-way passing states.
\end{abstract}

\section{Keywords}

bridge-train interaction, high-speed train, finite element model, single- and double-sided crossings, dynamic field test verification

\section{Introduction}

The high-speed rail transportation system plays a major role in most developed countries. Due to increased demands for such systems, it is required that various aspects of its operation be studied in depth to find and resolve potential problems. Bridges are important elements in high-speed tracks, and any hindrance to their operation could suspend the entire high-speed track, resulting in the loss of revenues. Due to various route characteristics, it is sometimes required to build skew bridges with various skew angles. The modal and dynamic behavior of bridges can be affected by skew angle due to different geometrical outlooks. The response of such bridges can also be affected by crossing speed, especially in bridges carrying double tracks.

In a paper published by the authors [1], the dynamic response of the bridge in various scenarios due to highspeed train crossings was studied. It was concluded that double train crossings (in this scenario, both tracks on a bridge being occupied by trains) with similar train speed resulted in higher responses because the bridge was excited in the vicinity of its natural frequencies. The main aim of this paper is to study the effect of skew angle on bridge responses due to the crossing of high-speed trains.

Yang et al. [2] studied the vibrations of a simple beam to the crossing of a high-speed train. The train was modeled as moving loads, and the Newmark-beta method was employed to solve the problem. Resonance and cancelation were also studied in this paper. A simple two-dimensional (2D) train-track interaction model was employed by Delgado and Santos [3] to study the effects of bridge mass and stiffness, span length, and rail corrugation on traintrack interaction. The interaction between the bridge and the passing trains was also studied by Liu et al. [4] using a 2D FEM, where the bridge was considered a simply-supported beam; the rotational degrees of freedom of the vehicle were ignored; and the axle loads were considered to be constant along all the axes. The problem of two parallel trains moving in opposite directions on a bridge was analytically solved by Vesali et al. [5] by considering simpli- 
fying assumptions. A series of moving loads modeled train loading, therefore, the train-track interaction was not studied. Effects of torsion were also not included since the bridge was assumed to be a simple beam, while two series of loads were applied on the beam. Field measurements and numerical simulations were used by Sue et. al [6] to measure the dynamic responses of a 40-year-old viaduct under the Japanese high-speed train passage (Shinkansen). The numerical model of the bridge was verified using experimental acceleration and displacement measurements. Furthermore, Abaqus was employed to model and analyze the bridge. Beam element was utilized to model structural members such as foundations, beams, and sleepers, while the bridge deck was modeled with shell elements. Nevertheless, the interaction of the components of the superstructure was not taken into account in this model. Meng et al. [7] performed comprehensive laboratory and numerical tests to study the response of a skewed steel bridge. The main aim of the project was to create a laboratory model of a skewed bridge for further laboratory tests, and calibration of a three dimensional finite element model. Results of static and dynamic loadings were compared to numerical values obtained from the model, indicating acceptable agreeability. Xia, Zhang, and Gao [8] performed field measurements to evaluate the responses of a simply-supported PC girders railway bridge under the high-speed train. The China-Star high-speed train passed over the bridge at a speed of 120 to $350 \mathrm{~km} / \mathrm{h}$. The results of this research revealed that this bridge had satisfactory resistance and the vehicle stability parameters were within allowable limits. Asheboa et al. [9] studied a skewed concrete bridge with continues spans. It was concluded that the dynamic amplification factor required for assessment is to some extent smaller than that proposed by guidelines. In another paper by Dinh et al. [10], a three-dimensional two-span continuous bridge with ballast superstructure was modeled. The span length was $40 \mathrm{~m}$ and a one-way passing scenario was considered. The model was validated by comparing the results with the analytical solution of a simply supported bridge. Dynamic evaluation of a coupled high-speed train and bridge system was also performed by Xia et al. [11]. A simple span box girder bridge with the span length of $32 \mathrm{~m}$ was studied. The results suggested that the effects of rail roughness on the dynamic responses of the bridge were significant. It was also concluded that an increase in rail roughness would decrease travel comfort at critical speeds. He et al. [12] examined a three-span bridge with continues spans and the skew angle of $45^{\circ}$.
It was shown that skew angle is an important factor affecting the dynamic and static behavior of a bridge. Adam and Salcher [13] also investigated the dynamic effect of high-speed trains on simple bridge structures. They evaluated the dynamic responses of single-span, two-span, and continual-span simply supported bridges for some transitional loading along the passing train axes. They also evaluated the maximum values of dynamic response in the bridge. Yan et al. [14] conducted a comprehensive review of the prevalence of high-speed railway bridges in the leading countries of this field. The structural systems of high-speed railway bridges as well as bridge seats were compared. It was concluded that the most common type of railway bridges is concrete box girders with a simple span and a span length less than $30 \mathrm{~m}$. Deng et al. [15] studied the response of skewed bridges in curved sections. Field tests and numerical models were employed to study a steel girder bridge. The bridge carried a single-track and had three continues spans. It was found that if the skew angle is less than $10^{\circ}$ and the ratio of bridge length to curve radius is less than 0.06 radian, it may be analyzed as a bridge in the straight section. A non-destructive monitoring method for high-speed bridges was proposed by Li et al. [16], in which strain results in some points of the bridge were used, subjected to high-speed train passing. The strain results were divided into two parts: force vibration and free vibration segments. The strain was identified in the analytical model by the evaluation of strain results of critical values in the force vibration. Moreover, the strain mode shapes were derived by the evaluation of strain results in the free vibration part. Ugarte et al. [17] investigated the dynamic behavior of Pergola's bridge deck subjected to passing loads near high-speed trains. First, a simple analytical method was employed to evaluate the complex dynamic behavior of Pergola's bridge, followed by a comparison of results of a simple analytic model with those of complex FEM. The acceptable precision of the analytical model was concluded. Giaa and Goicoleab [18] studied the vibrations of skewed bridges with small span lengths. Complex and simple methods were employed to solve the problem. Various parameters such as skew angle and span length were studied, and results revealed that skew angle has a significant effect on the response of the bridge.

It is evident from the literature that skew angle plays a significant role in the dynamic response of bridges, especially those in high-speed tracks. Specifically, its effect is of high importance on bridges carrying two tracks, on which 
single- and double-sided crossings in various directions may occur. The accurate 3D modeling of a bridge carrying two tracks, high-speed train, and their interaction was performed in this paper. Furthermore, the effect of crossing speed was studied and presented in various scenarios, including singleand double-sided crossings, for various skew angles.

\section{Research method}

In the present study, Abaqus finite element software was utilized to model the bridge and train. Hertz theory is also employed to consider the interaction between the two [19]. Subsequently, experimental displacement and acceleration records are used to calibrate the model, and sensitivity analysis is performed using the calibrated model.

The assumptions considered in this study are as follows:

- Train and bridge modeling is performed using the FEM.

- Each four-axis vehicle is described by 27 degrees of freedom.

- A two-lane simple span bridge with concrete box girder and concrete slab is considered.

- Modeling includes rails and spring-dampers related to pad and fastener.

- Various train crossing speeds are considered (120 to $350 \mathrm{~km} / \mathrm{h}$ ).

- Single- and double-sided crossing scenarios are taken into account.

- The bridge is modeled with skew angles of $0,15,30$, and $45^{\circ}$.
The goals of this research are as follows:

- Assessing the effects of skew angle on modal shapes and main natural frequencies.

- Evaluating the effects of skew angle on bridge responses, including acceleration and deflection at various locations for various crossing speeds and single- or double-sided crossings.

- Comparing critical crossing speeds on skewed bridges, and determining the minimum skew angle for which the bridge will be considered a bridge with the skew angle of zero.

According to the assumptions and goals presented above, the paper will follow as shown in Fig. 1.

\section{Bridge and train characteristics}

Yan et al. [2] investigated the dispersion of the structural system as well as the length of high-speed railway bridges in countries with this technology, including China, Japan, France, Germany, Spain, and Italy. According to this study, the bridge structure in high-speed railway mainly adopts simply-supported PC box-girders; as such, $90 \%$ of the bridges are of this type only on the ShanghaiBeijing HSR of China.

The studied bridge in this paper is a simply-supported concrete box girder with the span length of $24.6 \mathrm{~m}$ and 28 spans. Acceleration and displacement in two spans of the bridge were recorded by Xia et.al [11], subjected to highspeed trains with various crossing speeds. The cross-section image of the bridge is presented in Fig. 2.

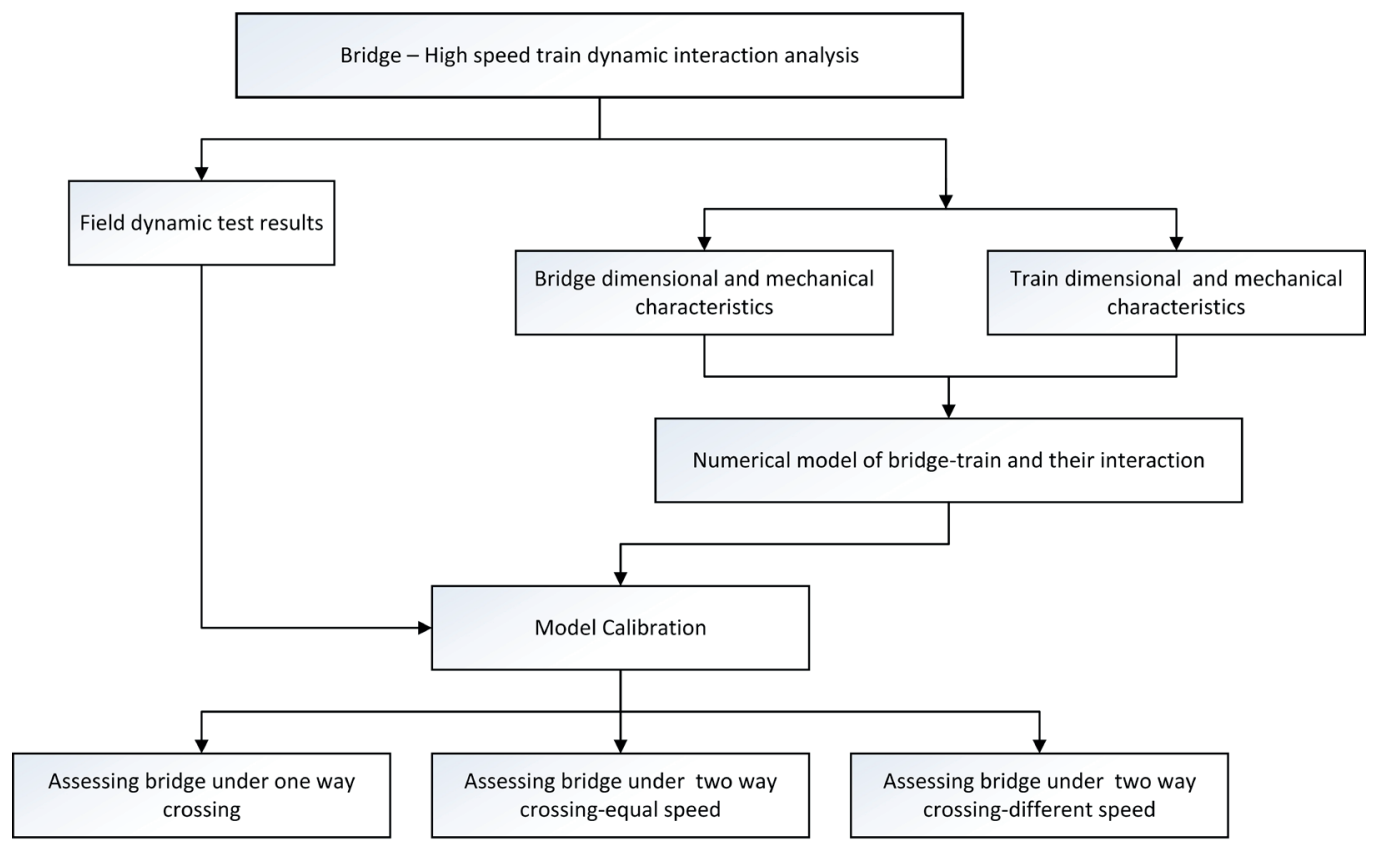

Fig. 1 Schematic representation of the research method 


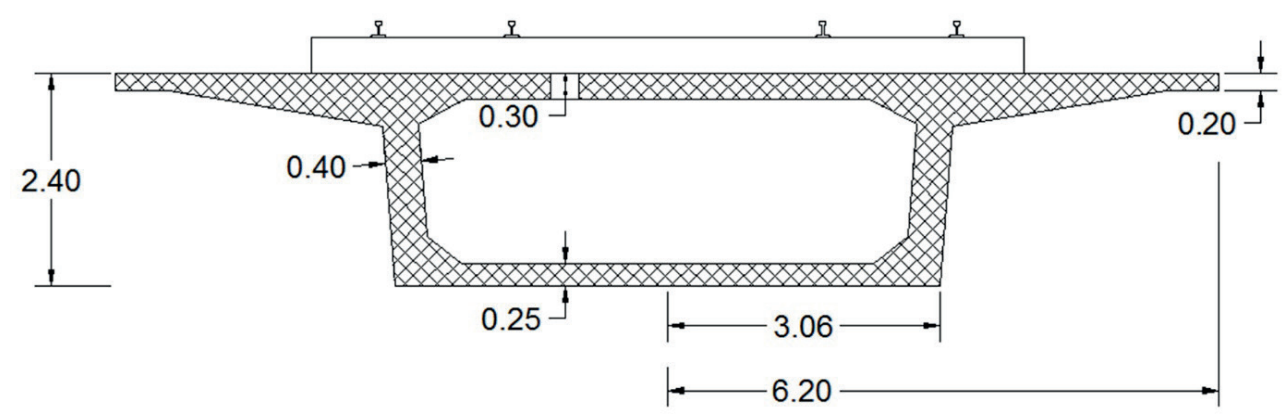

Fig. 2 Cross section of the 24m-span PC box girder (All measurements are in units of m)

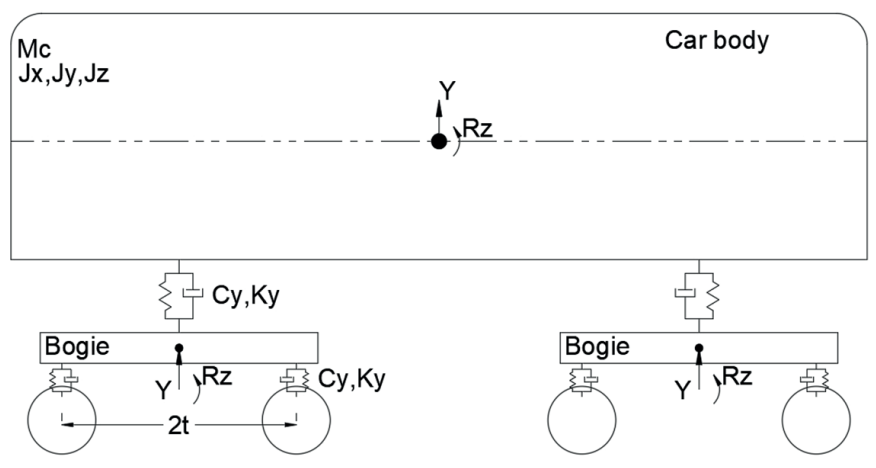

(a) Side view

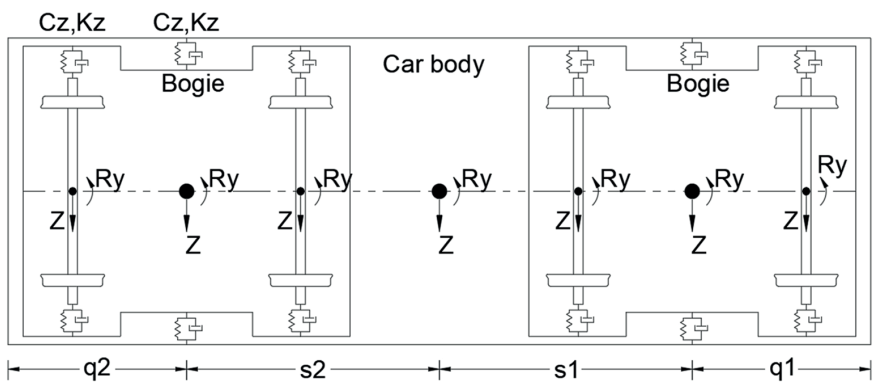

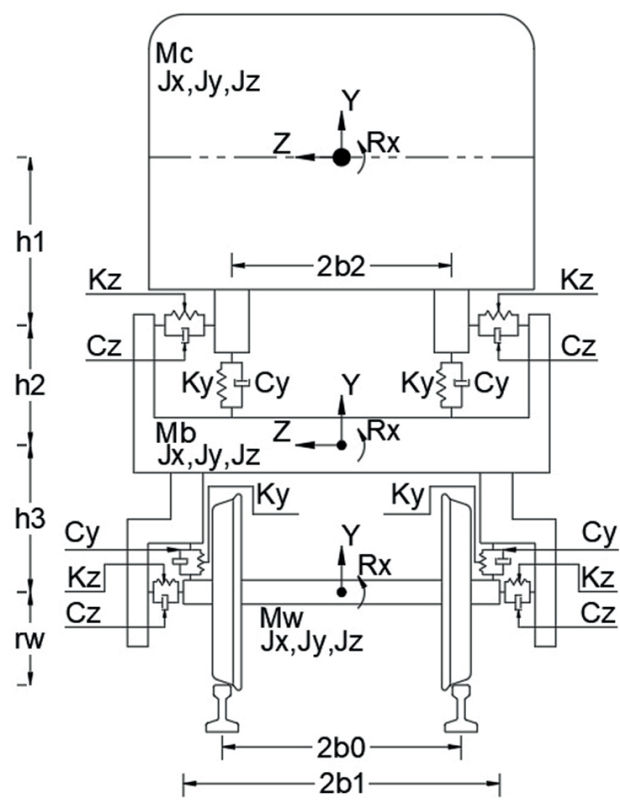

(c) Front view

(b) Top view

Fig. 3 Model, dimensions, and parameters of a train's car

Table 1 Mechanical properties and dimensions of an independent train car

\begin{tabular}{|c|c|c|c|c|}
\hline Description & Name & Unit & Power car & Passenger cars \\
\hline Car-body dimensions & $\mathrm{s} 1 ; \mathrm{s} 2 ; \mathrm{q} 1 ; \mathrm{q} 2 ; \mathrm{h} 1$ & $\mathrm{~m}$ & $5.73 ; 5.73 ; 6.8 ; 3.75 ; 0.75$ & $9 ; 9 ; 3.75 ; 3.75 ; 0.75$ \\
\hline Mass of car-body & $\mathrm{Mc}$ & ton & 63.98 & 43.82 \\
\hline Car-body inertia moments & $\mathrm{Jx} ; \mathrm{Jy} ; \mathrm{Jz}$ & ton. $\mathrm{m}^{2}$ & $59.40,2505.3,2485.4$ & $23.20,2100.0,2080.0$ \\
\hline Mass of bogie & $\mathrm{Mb}$ & ton & 3.434 & 3.04 \\
\hline Bogie inertia moments & $\mathrm{Jx} ; \mathrm{Jy} ; \mathrm{Jz}$ & ton. $\mathrm{m}^{2}$ & $1.766,2.453,4.905$ & $1.580,2.344,3.934$ \\
\hline Secondary suspension stiffness & $\mathrm{Kz}$; Ky & $\mathrm{KN} / \mathrm{m}$ & $297.2,1245.87$ & $176.0,265.0$ \\
\hline Secondary suspension damping & $\mathrm{Cz} ; \mathrm{Cy}$ & $\mathrm{KNS} / \mathrm{m}$ & $98.1,98.1$ & $39.2,45.12$ \\
\hline Secondary suspension dimensions & $\mathrm{b} 2 ; \mathrm{h} 2$ & $\mathrm{~m}$ & $1.23,0.42$ & $1.23,0.42$ \\
\hline Primary suspension stiffness & $\mathrm{Kz} ; \mathrm{Ky}$ & $\mathrm{KN} / \mathrm{m}$ & $2452.5,1226.25$ & $2350.0,590.0$ \\
\hline Primary suspension damping & $\mathrm{Cz} ; \mathrm{Cy}$ & $\mathrm{KNS} / \mathrm{m}$ & $98.10,29.43$ & $58.86,19.62$ \\
\hline Mass of wheel-axle & Mw & ton & 1.776 & 1.776 \\
\hline Wheel-axle moment & $\mathrm{Jx} ; \mathrm{Jy} ; \mathrm{Jz}$ & ton. $\mathrm{m}^{2}$ & $1.138,1.138,0.00785$ & $1.138,1.138,0.00785$ \\
\hline Primary suspension \& wheel & b0; b1; h3; t; rw & $\mathrm{m}$ & $0.75,1.0,0.2,1.25,0.455$ & $0.75,1.0,0.2,1.25,0.455$ \\
\hline
\end{tabular}




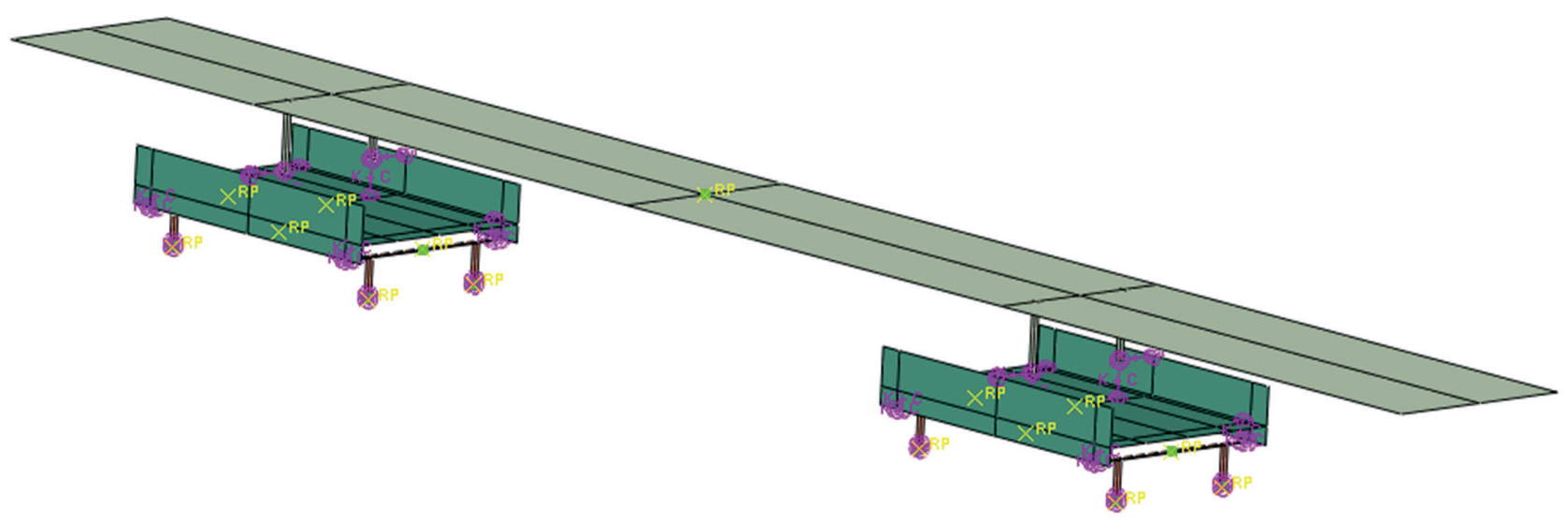

Fig. 4 Vehicle modeling

Based on the field study conducted on the case study bridge [11], the train selected for the present work is the China-Star high-speed train. In the validation stage, the passing train consists of two locomotives and nine wagons, and in the sensitivity analysis, the train consists of one locomotive and two wagons. The axle loads of locomotive and wagon are 19.5 and 14.25 tons, respectively. Dimensions and mechanical properties of the train car (27-DOFs dynamic system) are described in Fig. 3 and Table 1.

Shell elements are employed in the FE model, while solid elements are used to model concrete slab-track and rails. Shell elements are also utilized to model Wagons, bogies, and axles, considering discrete rigid properties and rotational inertia characteristics. Furthermore, spring and viscous dampers are incorporated to model connections and wheel-rail interaction is modeled employing Hertz-spring. An illustration of the vehicle FE model is presented in Fig. 4.

\subsection{Material damping model}

In order to model the bridge inherent damping material, the Rayleigh damping method is utilized. Damping ratio is $2.5 \%$ as concluded from test results [11]. Thus:

$[C]=\alpha[M]+\beta[K]$.

$\xi_{n}=\frac{\alpha}{2 \omega_{n}}+\frac{\beta \omega_{n}}{2}$

$\left\{\begin{array}{l}\alpha \\ \beta\end{array}\right\}=\frac{2 \xi}{\omega_{1}+\omega_{2}}\left\{\begin{array}{c}\omega_{1} \omega_{2} \\ 1\end{array}\right\}$.

In which $[C],[M]$ and $[K]$ are damping, mass, and stiffness matrices, respectively. Moreover, $\alpha$ and $\beta$ are damping coefficients, which are proportional to mass and stiffness; $\xi$ is damping ratio; and $\omega_{1}$ and $\omega_{2}$ are natural frequencies.

\subsection{Absorbent boundaries}

Because of the limited length of rails in FEM, the absorbent boundaries are modeled to absorb the incident waves at the end of the rails and prevent them from returning. In this research, the absorbed boundaries are the speed-dependent viscose damper type suggested by Lysmer and Kuhlemeyer [20] for solving dynamical problems.

The constants of damper per unit area in the vertical direction to the surface are obtained from the Eqs. (4-5).

$C_{n}=\rho V_{p}$

$V_{p}=\frac{3.4 V_{s}}{\pi(1-v)}$,

where $\rho$ is mass per unit volume, $V_{p}$ is $\mathrm{P}$-wave speed, $C_{n}$ is a constant of per unit area in the vertical direction to the surface, $v$ is Poisson's ratio and $V_{s}$ is shear wave speed. The absorbent boundaries model is illustrated in Fig. 5 .

\subsection{Boundary condition}

To simplify the calculation, it is assumed in some research projects [6-10] that the entrance and outlet section of the span have zero displacements with respect to the bridge. In this present study, to evaluate the effects of lateral spans, two additional side-spans are modeled before and after the considered span, as depicted in Fig. 6.

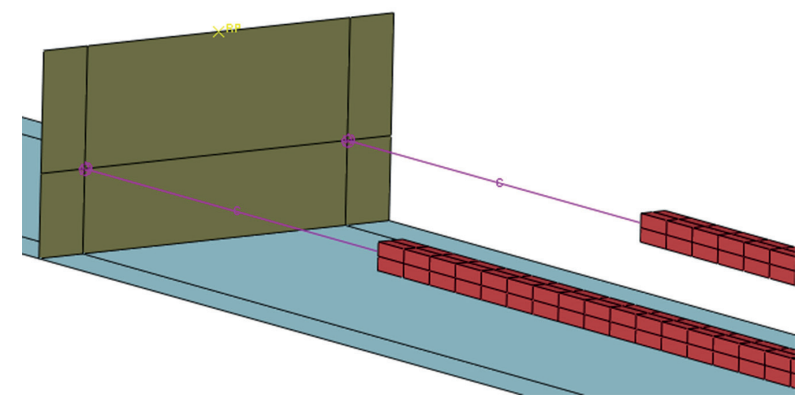

Fig. 5 Absorbent boundaries model 


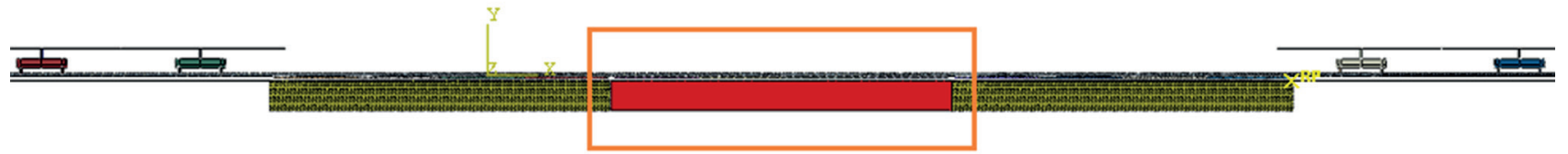

Fig. 6 The main and additional side-spans of the bridge model

\section{Modal analysis and optimization of meshing dimensions}

Mesh size is one of the parameters effective on FEM analyses. Although smaller elements lead to the higher precision of the model, they require more time for analysis. In this research, modal analysis is performed with various mesh sizes on the bridge model to determine the optimum meshing dimensions, and the calculated modal frequencies are listed in Table 2.

As shown in Table 2, the natural frequencies of the first four modes converge and do not experience any changes by decreasing the mesh sizes from 20 to $15 \mathrm{~cm}$. Therefore, the optimal mesh size is selected as $15 \mathrm{~cm}$ in the analyses.

\section{Verification of the numerical model}

Model verification using the results of the field test is presented in this section. Modal analysis results and experimental displacement records are used for verification. The time history of displacement is considered in the bridge middle span subjected to a high-speed China-Star train passing with a speed of $260 \mathrm{~km} / \mathrm{h}$. The train used in the validation selected based on the passing train in the field test [8] consisted two locomotives and nine wagons, with the axle load of the locomotive and wagons being 19 tons and 14.5 tons, respectively. Comparison of the experimental and numerical modal is presented in Table 3.

As shown in Table 3, experimental and numerical first modal frequencies are very close. A comparison between the displacements at the mid-span in FEM and field test is given in Fig. 7.

\begin{tabular}{lcccc}
\multicolumn{5}{c}{ Table 2 Modal frequency results } \\
\hline \multicolumn{5}{c}{ Frequency $(1 / \mathrm{sec})$} \\
Max mesh size $(\mathrm{cm})$ & $1^{\text {st }}$ Mode & $2^{\text {nd }}$ Mode & $3^{\text {th }}$ Mode & $4^{\text {th }}$ Mode \\
\hline 100 & 7.94 & 11.09 & 19.02 & 20.08 \\
75 & 7.86 & 11.11 & 18.97 & 20.01 \\
50 & 7.97 & 11.11 & 18.93 & 19.92 \\
30 & 7.72 & 11.1 & 18.94 & 19.84 \\
25 & 7.71 & 11.1 & 18.89 & 19.84 \\
20 & 7.68 & 11.09 & 18.88 & 19.82 \\
15 & 7.68 & 11.09 & 18.88 & 19.81 \\
\hline
\end{tabular}

Table 3 A comparison between modal frequencies in FEM modeling and field test

\begin{tabular}{lcc}
\hline \multirow{2}{*}{ Span } & \multicolumn{2}{c}{ Modal frequency $(\mathrm{Hz})$} \\
& Field test & FEM \\
\hline $22^{\text {th }}$ & 7.65 & 7.68 \\
$23^{\text {th }}$ & 7.70 & \\
\hline
\end{tabular}

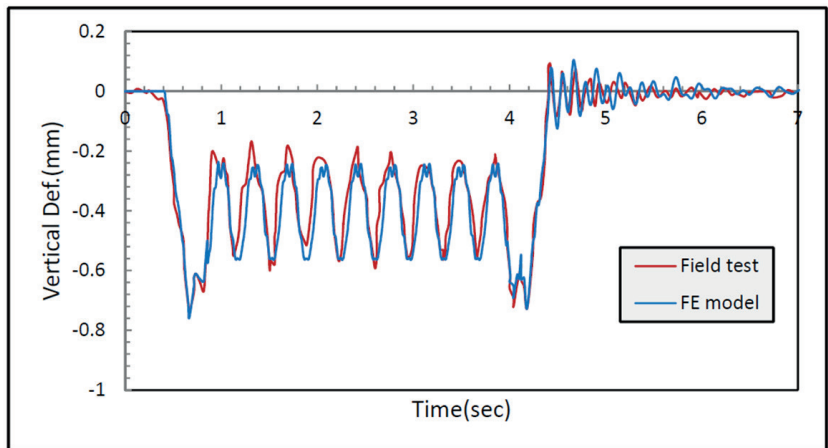

Fig. 7 Displacement time histories of mid-span obtained by numerical model and field tests for the train speed of $260 \mathrm{~km} / \mathrm{h}$

As seen from Fig. 7, experimental and numerical results are almost identical, suggesting the modeling behavior accuracy of the prepared FEM.

\section{Results of sensitivity analysis}

After proving the behavior accuracy and the results of FEM, the results of sensitivity analysis are presented in this section. One of the most important parameters in the analysis of dynamic issues is excitation frequency. According to the passing speeds and loading intervals, the excitation frequency value is calculated by the Eq. (6).

$f=\frac{V}{S}$,

where $V$ denotes passing speed and $S$ represents the distance between loading points. The excitation frequencies of the train are given in Table 4.

The results of displacement and acceleration in different points of the bridge such as the bridge mid-span and the bridge quarter-span are illustrated in Fig. 8. In this figure, PL and PR indicate the beginning and the end points of the main-span, points marked with PM show the mid-span cross beam section, and points marked with PSL and PSR demonstrate entrance and outlet quarter-span cross beam 
Table 4 The excitation frequencies of passing train at various speeds

\begin{tabular}{|c|c|c|c|c|c|}
\hline \multirow[b]{4}{*}{$\mathrm{V}(\mathrm{km} / \mathrm{h})$} & \multirow[b]{4}{*}{$\mathrm{V}(\mathrm{m} / \mathrm{sec})$} & \multicolumn{2}{|c|}{ Power car } & \multicolumn{2}{|c|}{ Passenger cars } \\
\hline & & Axles inv(m) & Bogie inv(m) & Axles inv(m) & $\operatorname{Bogie} \operatorname{inv}(m)$ \\
\hline & & 3 & 11.46 & 2.56 & 18 \\
\hline & & \multicolumn{2}{|c|}{ Frequency(Hz) } & \multicolumn{2}{|c|}{ Frequency(Hz) } \\
\hline 120 & 33.3 & 11.11 & 2.91 & 13.02 & 1.85 \\
\hline 150 & 41.7 & 13.89 & 3.64 & 16.28 & 2.31 \\
\hline 180 & 50.0 & 16.67 & 4.36 & 19.53 & 2.78 \\
\hline 220 & 61.1 & 20.37 & 5.33 & 23.87 & 3.40 \\
\hline 260 & 72.2 & 24.07 & 6.30 & 28.21 & 4.01 \\
\hline 300 & 83.3 & 27.78 & 7.27 & 32.55 & 4.63 \\
\hline 350 & 97.2 & 32.41 & 8.48 & 37.98 & 5.40 \\
\hline
\end{tabular}

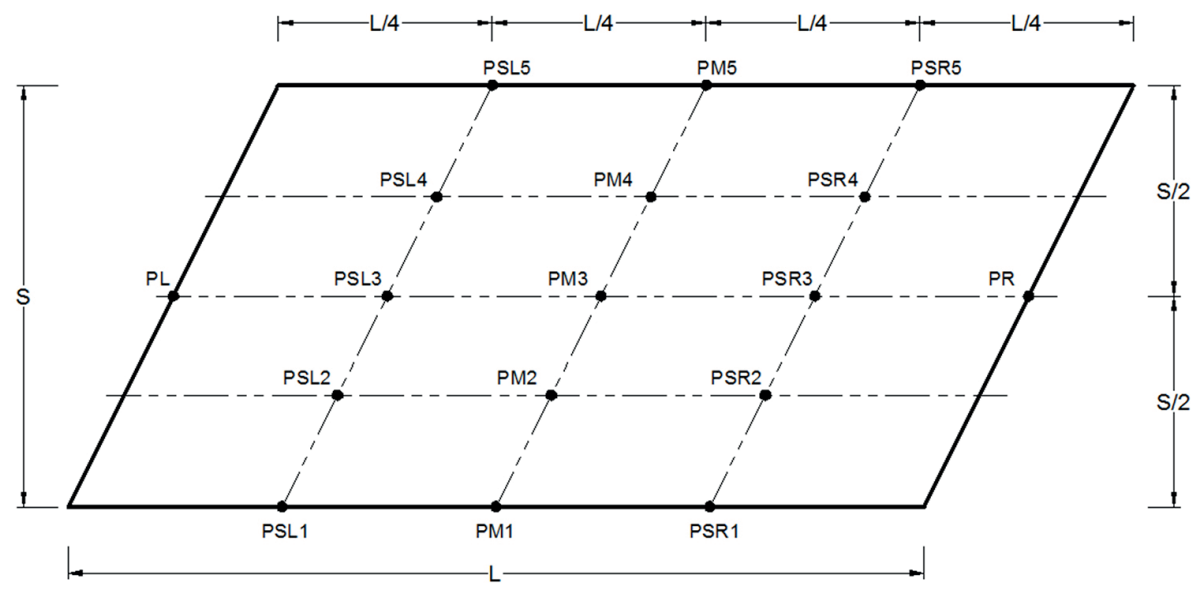

Fig. 8 The target record points in the bridge deck

section on both sides of the main-span. Points marked with PL, PSL3, PM3, PSR3, and PR are located on the longitudinal center-line. It should be mentioned that PSR4, PM4, PSL4 and PSL2, PM2, and PSR2 are in the middle of two tracks in both directions. Finite element models of bridges with various skew degrees are presented in Fig. 10.

\subsection{Modal Shapes for various skew angles}

Modal behavior and natural frequencies are two main behavioral characteristics of any system. Changes of shape and stiffness of the bridge in the transverse direction in skewed bridges could result in a change in the modal shape and modal frequencies of the bridge. The first four modal shapes and frequencies of bridges with different skew angles are compared in Fig. 9 and Table 5.

Evidently, skew angle not only affects natural frequencies, but also modal shapes. The first three modal shapes of straight bridges and skewed bridges with skew angles of 15 and $30^{\circ}$ are almost identical, while the $4^{\text {th }}$ modal shapes are different. In case of a $45^{\circ}$ skew angle, only the first modal shape is similar to that of a straight bridge. The same can be observed for natural frequencies. According to results, the natural frequencies of a skewed bridge with a skew angle less than $15^{\circ}$ are almost the same those of a straight bridge.

\subsection{Span longitudinal center-line results for various crossing speeds}

Trains crossing speed is an influential factor on bridge responses. The same holds true, and is even more significant, for high-speed trains. Acceleration values and mid-span deflection for various crossing speeds and skew degrees

Table 5 First four natural frequencies and mode shapes of bridges with different skew angles

\begin{tabular}{|c|c|c|c|c|c|c|c|c|}
\hline & \multicolumn{8}{|c|}{ Bridge skew angle } \\
\hline & \multicolumn{2}{|c|}{$0^{\circ}$} & \multicolumn{2}{|c|}{$15^{\circ}$} & \multicolumn{2}{|c|}{$30^{\circ}$} & \multicolumn{2}{|c|}{$45^{\circ}$} \\
\hline & $\operatorname{Fr}(\mathrm{Hz})$ & M.sh & $\operatorname{Fr}(\mathrm{Hz})$ & M.sh & $\operatorname{Fr}(\mathrm{Hz})$ & M.sh & $\operatorname{Fr}(\mathrm{Hz})$ & M.sh \\
\hline 1thMode & 7.7 & S1 & 7.1 & S1 & 7.1 & S1 & 6.9 & $\mathrm{~S} 1$ \\
\hline 2thMode & 11.1 & $\mathrm{~S} 2$ & 11.7 & $\mathrm{~S} 2$ & 11.7 & S2 & 12.2 & S6 \\
\hline 3thMode & 18.9 & $\mathrm{~S} 3$ & 18.0 & S3 & 16.2 & S3 & 12.6 & S7 \\
\hline 4thMode & 19.8 & S4 & 19.3 & S5 & 17.7 & S5 & 13.7 & $\mathrm{~S} 8$ \\
\hline
\end{tabular}




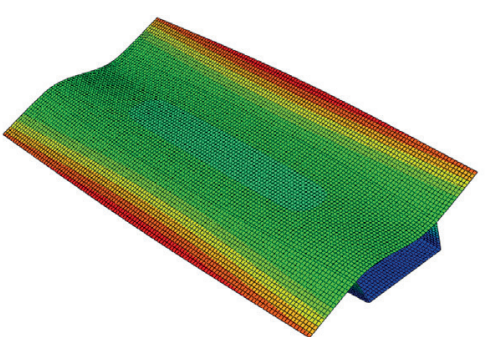

$\mathrm{S} 1$

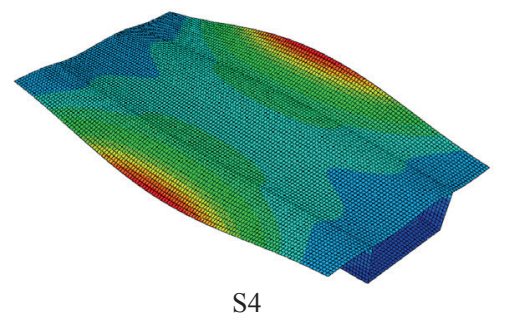

S4

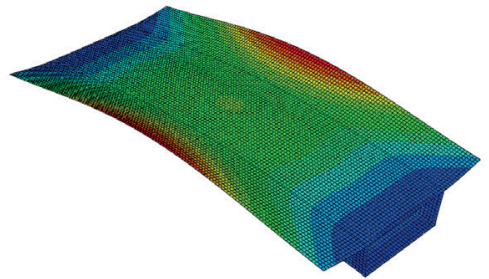

S2

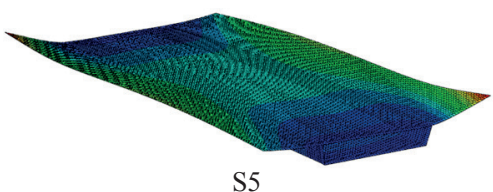

S5

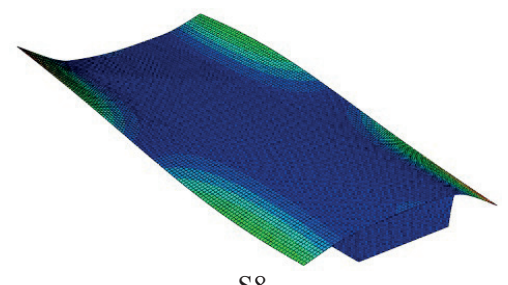

S8

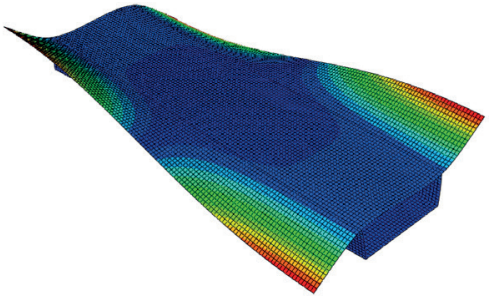

S3

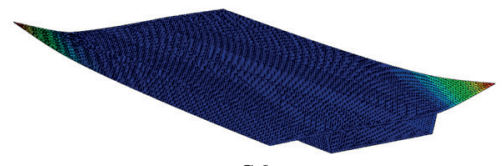

S6

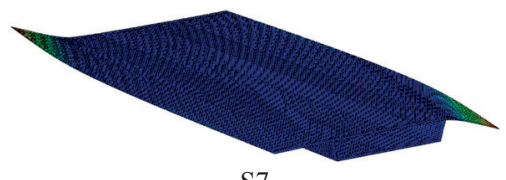

S7

Fig. 9 Mode shapes of bridges with different skew angles

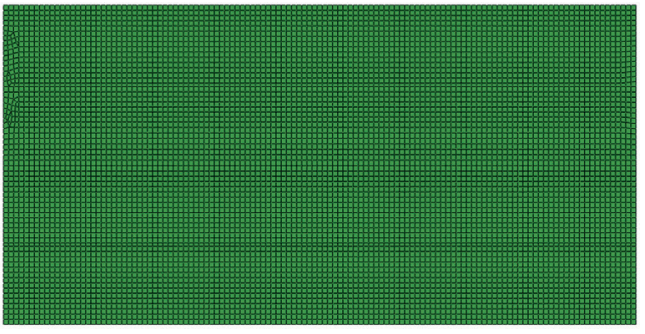

Skew angle: $0^{\circ}$

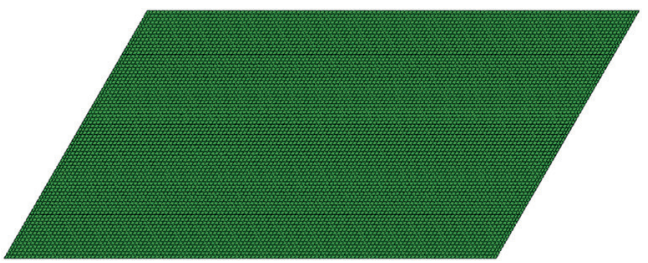

Skew angle: $30^{\circ}$

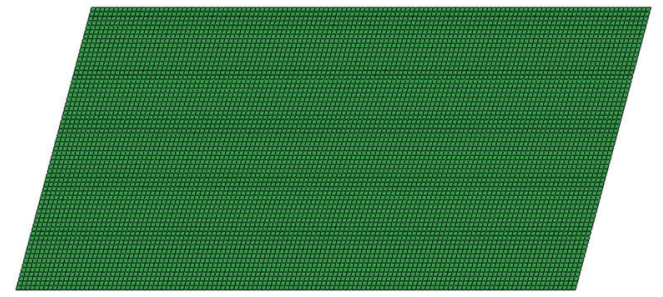

Skew angle: $15^{\circ}$

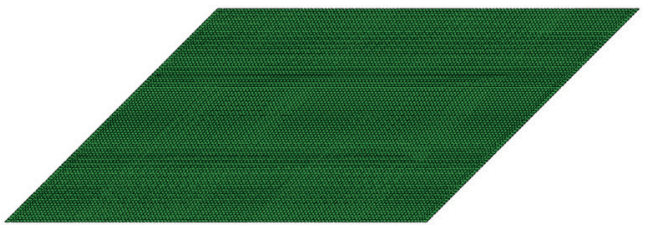

Skew angle: $45^{\circ}$

Fig. 10 Finite element model of the bridge for various skew degrees

are presented in this section. In Fig. 11, maximum acceleration and deflection of a straight bridge for single- and double-sided crossings with similar speeds are presented. Figs. 12 and 13 depict maximum acceleration and deflection of mid-span for various speeds and skew angles.

It is clear that the difference in maximum deflection of mid-span for single- and double-sided crossings tends to decrease as the skew angle increases. According to results, deflection of a $15^{\circ}$ skewed bridge is almost similar to that of a straight bridge. It is, therefore, possible to define the skew angle of $15^{\circ}$ as the threshold, and bridges with skew angles smaller than this threshold may be considered as straight bridges. Nevertheless, for skew angles of 30 and $45^{\circ}$, maximum deflection tends to decrease. Another important factor is the speed at which maximum values are observed, which is not constant for various skew degrees. While maximum displacement for a $15^{\circ}$ skew bridge occurs at the crossing speed of $260 \mathrm{~km} / \mathrm{h}$, that of $30^{\circ}$ and $45^{\circ}$ skew bridges occurs at speeds of 300 to 350 $\mathrm{km} / \mathrm{h}$, respectively. The main reason behind this observation is the alteration of the modal frequency of the bridge, which in turn alters the speed at which resonance occurs. 


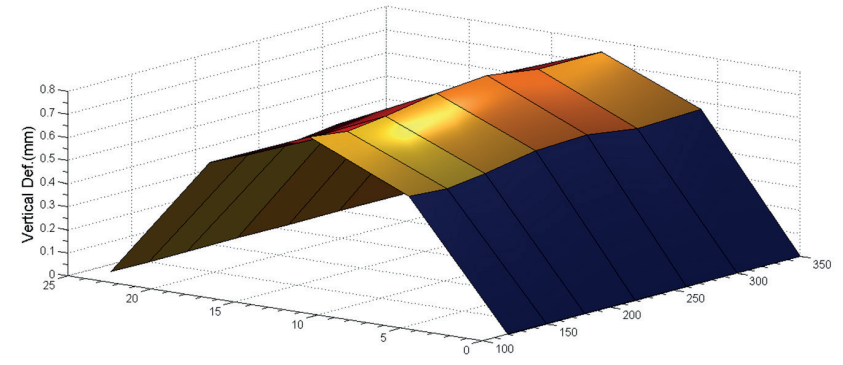

Bridge Length(m)

One-way passing - deflection

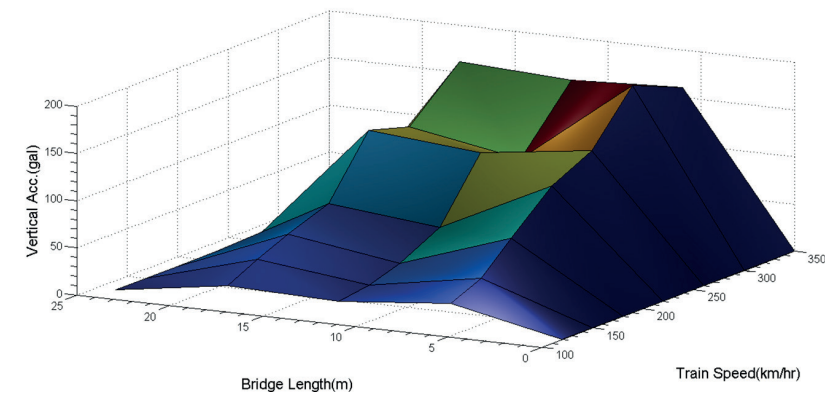

One-way passing - acceleration

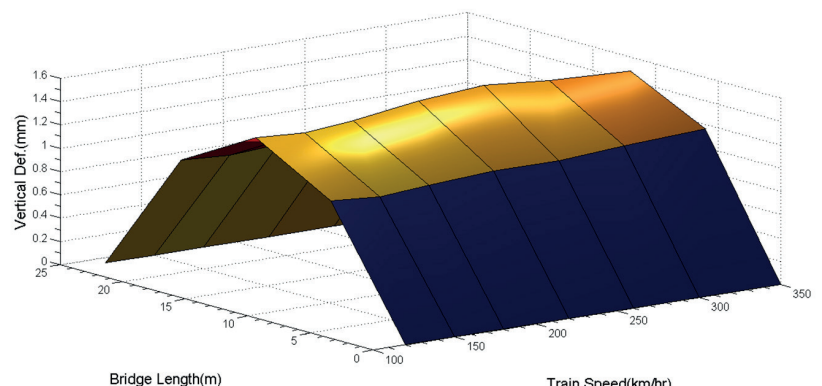

Two-way passing - deflection

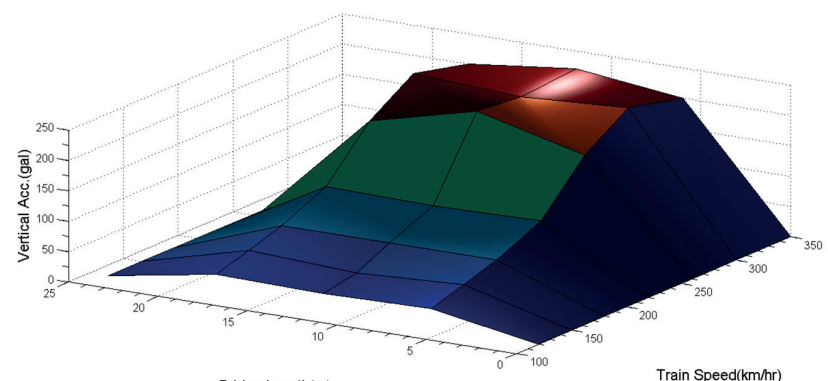

Two-way passing - acceleration

Fig. 11 Maximum acceleration and deflection of the longitudinal center-line for the straight bridge

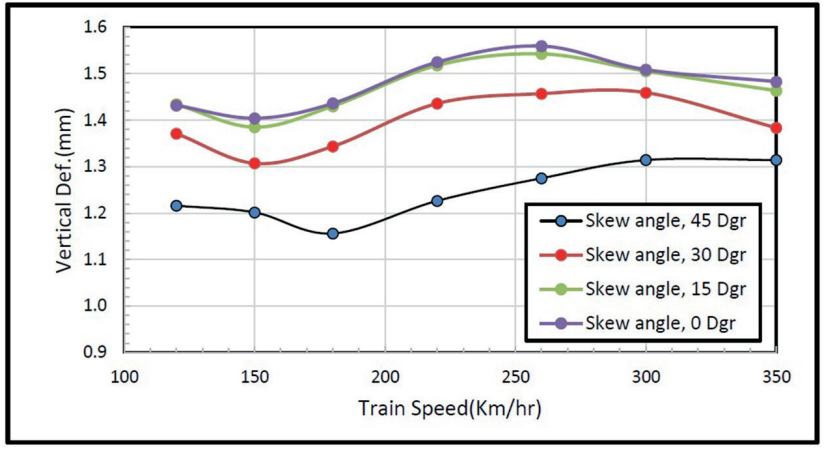

Two-way passing - deflection

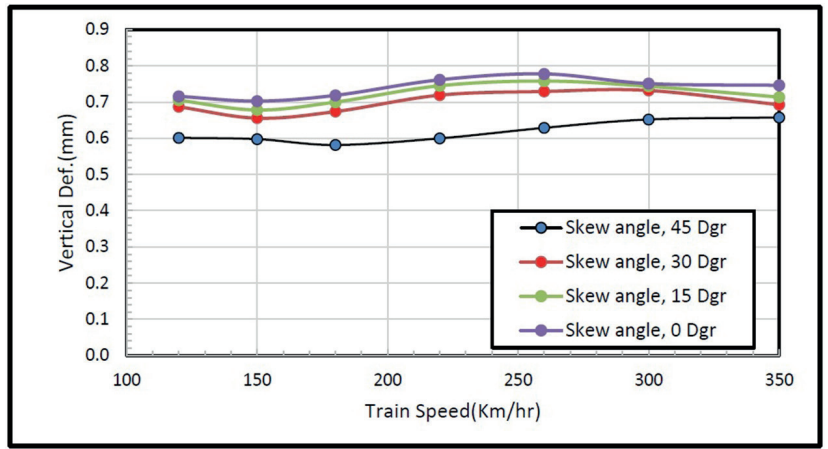

One-way passing - deflection

Fig. 12 Maximum deflection of the bridge at the longitudinal center-line of the span for various crossing speeds

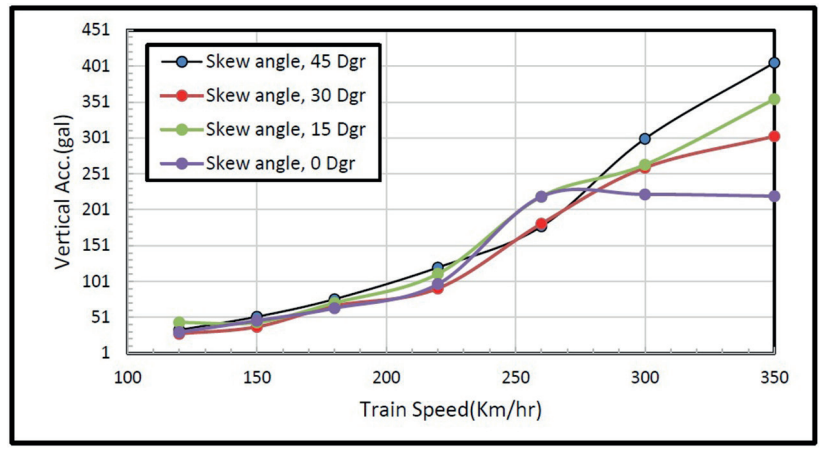

Two-way passing - acceleration

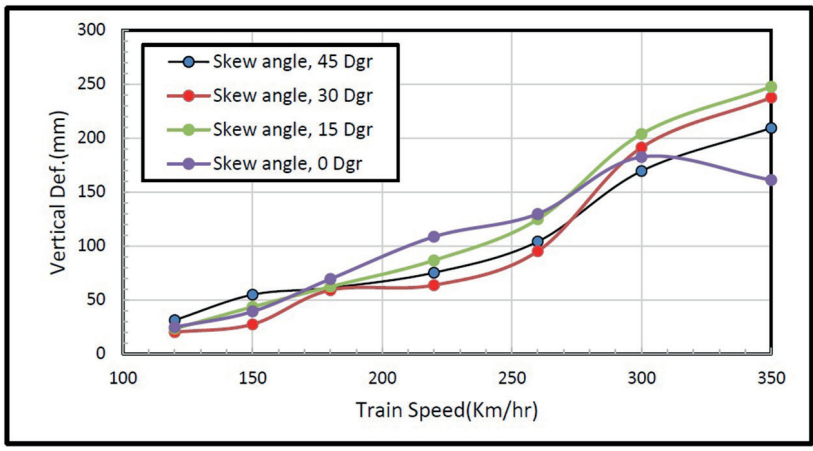

One-way passing - acceleration

Fig. 13 Maximum acceleration of the bridge at the longitudinal center-line of the span for various crossing speeds 
Nevertheless, the same cannot be stated for acceleration values as they significantly vary in single- and double-sided crossings. In single-sided crossings, due to the unsymmetrical loading of the bridge, lateral twist mode shapes are excited, while for double crossings, longitudinal and diagonal twist shapes are dominant. Acceleration values tend to increase for both scenarios; yet, the corresponding speed at which maximum accelerations are observed differ for various skew angles. For a straight bridge, maximum accelerations are observed at the speed of $260 \mathrm{~km} / \mathrm{h}$, whereas those of skewed bridges have a positive correlation with speed, meaning that they increase for higher crossing speeds.

\subsection{Cross beam section results for various crossing speeds and skew angles}

Another factor studied in this paper is the response of the bridge in its cross-sections. Cross beam section in the middle of the bridge, quarter of the bridge entrance, and quarter of the bridge exit are considered. Figs. 14 and 15

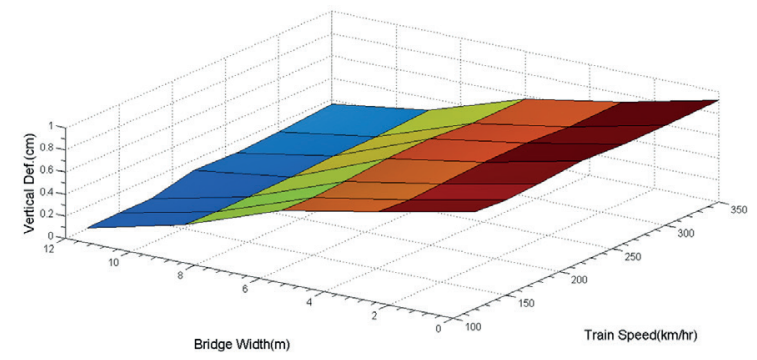

Entrance quarter-span cross beam deflection

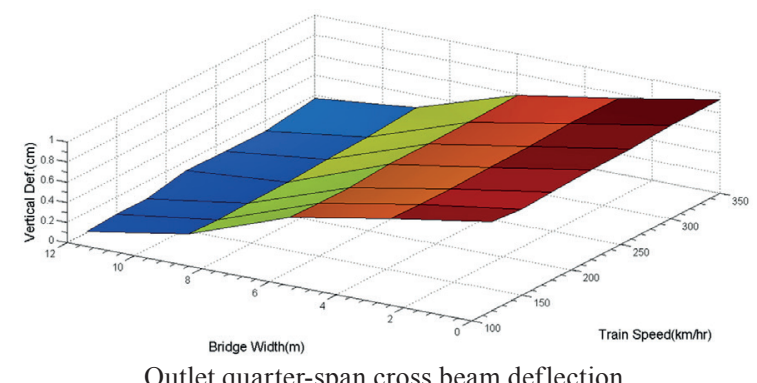

Outlet quarter-span cross beam deflection

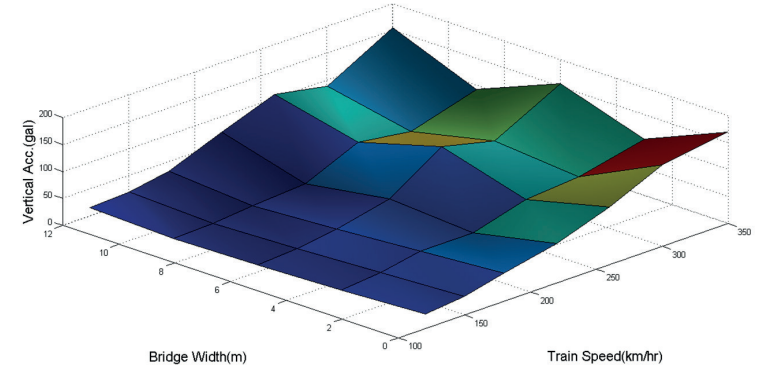

Mid-span- cross beam acceleration present the deflection and acceleration results for the cross beam section of the straight bridge, and those of various skewed bridges are also are given in Figs. 16-18.

Based on Fig. 16, for a single-sided crossing scenario, the maximum deflection of cross beam section in bridge's entrance is not significantly affected by skew angle. Yet for the double crossing scenario, maximum deflection tends to decrease as the skew angle increases. Acceleration values are correlated with speed. The higher the crossing speed, the higher the acceleration values. Acceleration values for the $45^{\circ}$ skew bridge are the highest from among studied bridges.

According to Fig. 17, for single- and double-sided crossings, the maximum deflection of the cross beam section of the middle of the bridge tends to decrease for higher skew angles. Moreover, results are correlated with speed, meaning that the crossing speed at which maximum deflection is observed is not constant for various skew angles. However, for a skew angle less than $15^{\circ}$, results are almost identical to a straight bridge.
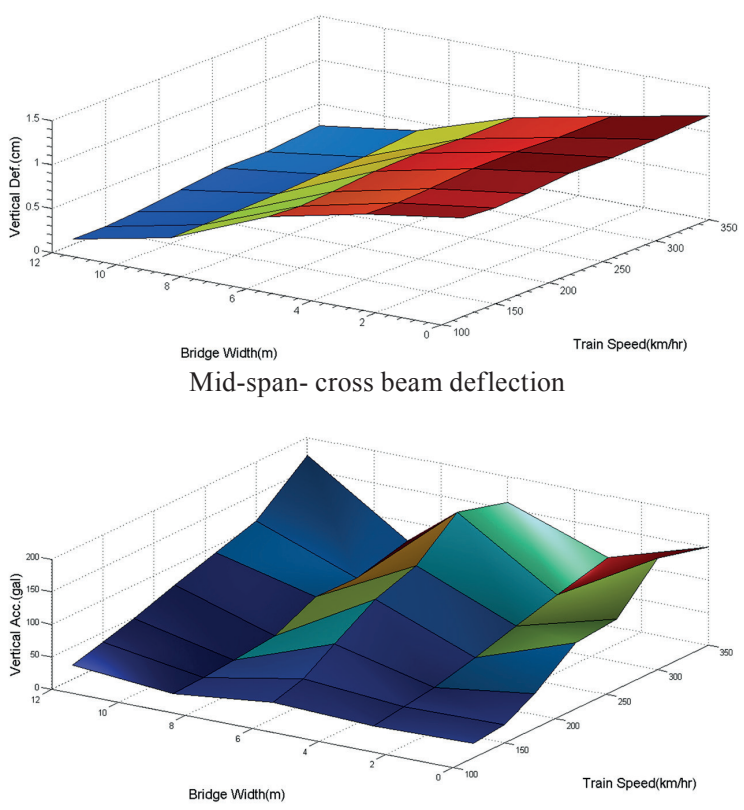

Entrance quarter-span cross beam acceleration

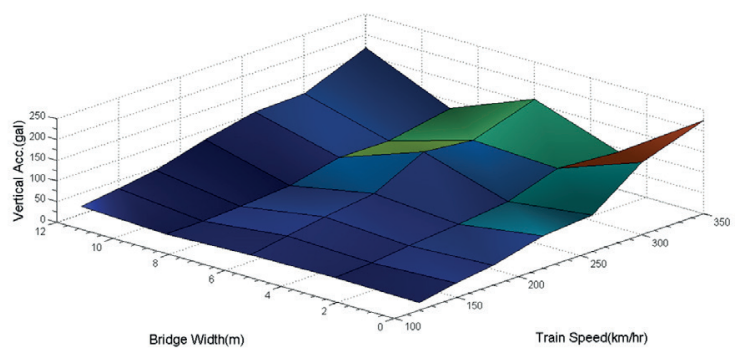

Outlet quarter-span cross beam acceleration

Fig. 14 Maximum acceleration and deflection of the bridge at cross beam sections for single-sided crossing-straight bridge 


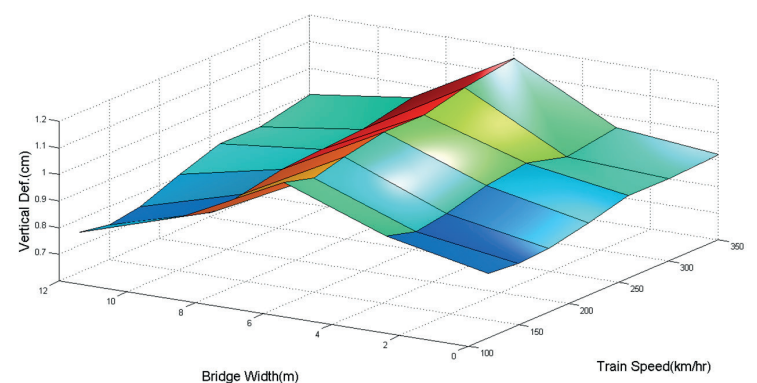

Entrance quarter-span cross beam deflection

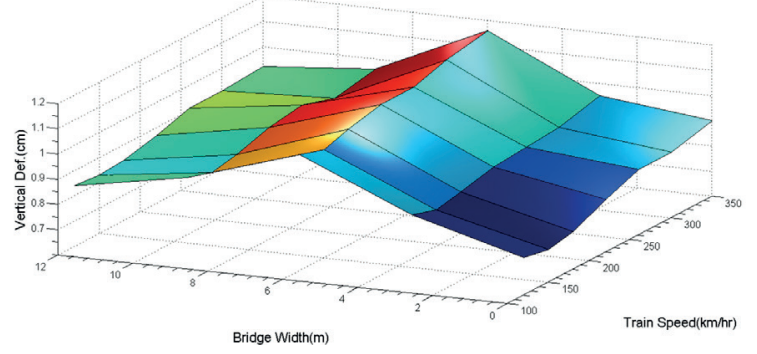

Outlet quarter-span cross beam deflection

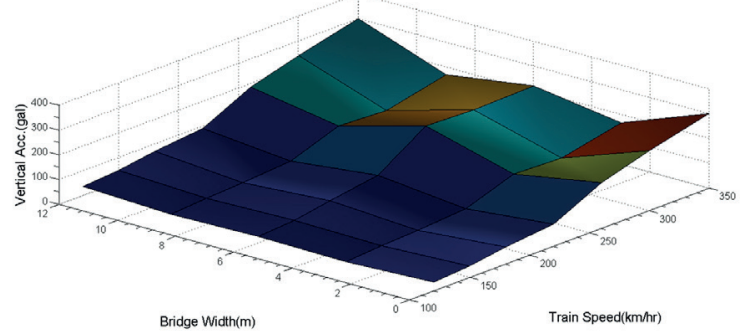

Mid-span- cross beam acceleration

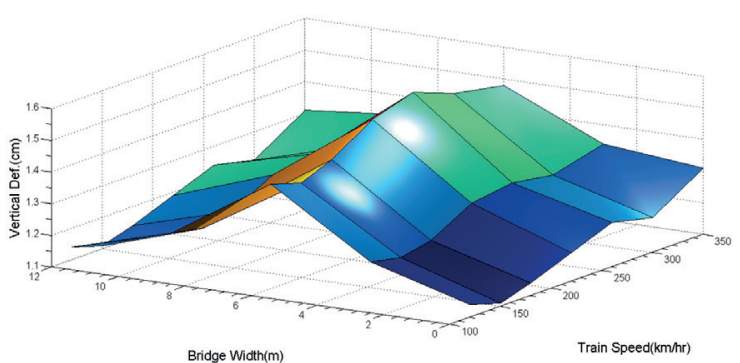

Mid-span- cross beam deflection

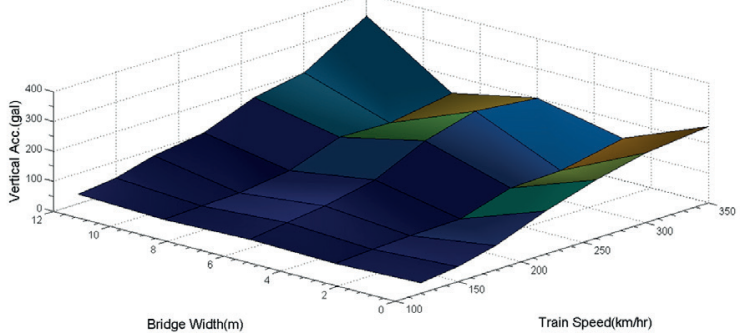

Entrance quarter-span cross beam acceleration

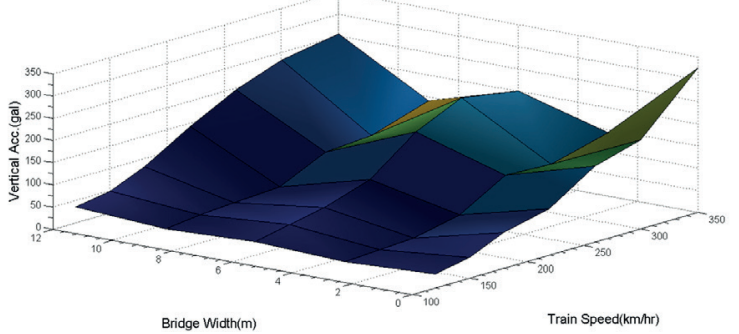

Outlet quarter-span cross beam acceleration

Fig. 15 Maximum acceleration and deflection of the bridge at cross beam sections for double-sided crossing-straight bridge

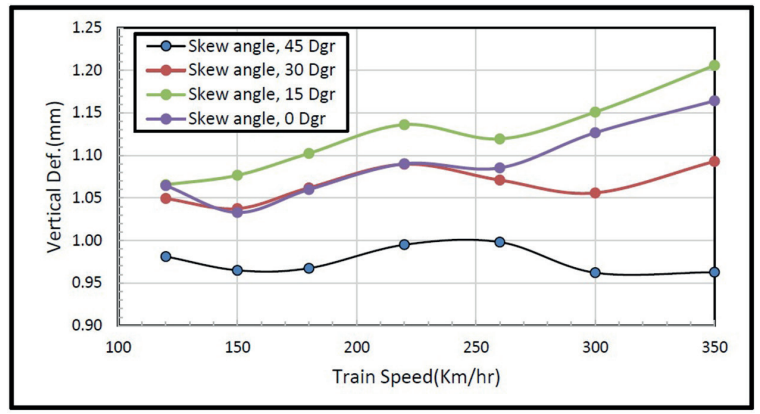

Two-way Passing

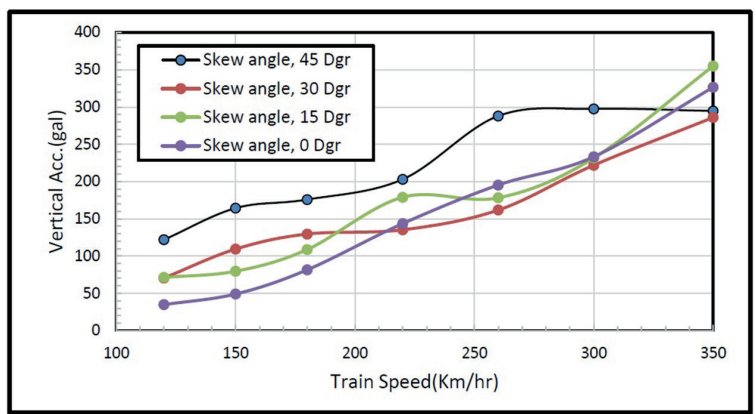

Two-way Passing

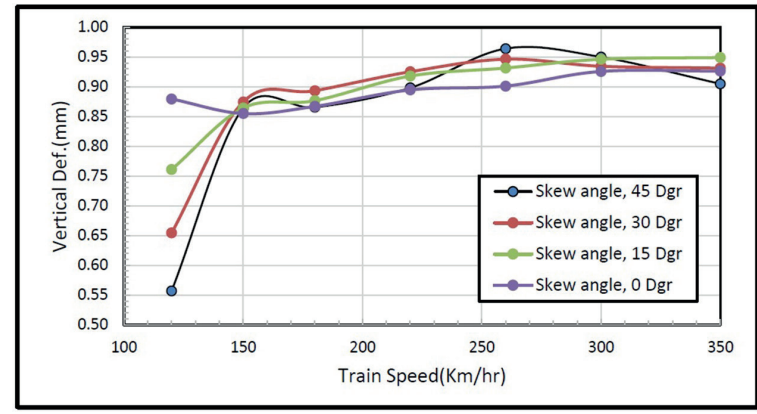

One-way Passing

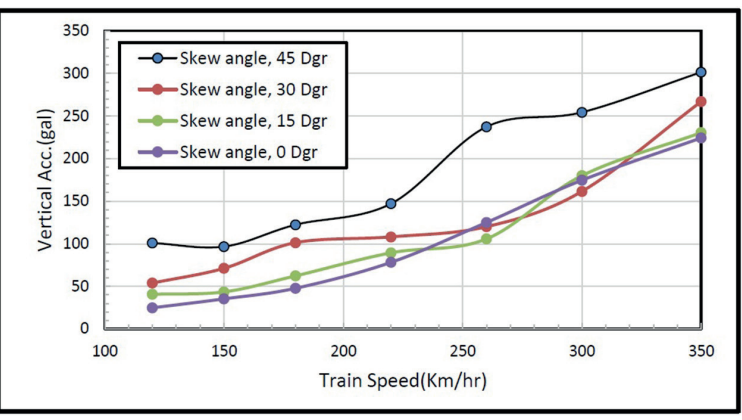

One-way Passing

Fig. 16 Deflection and acceleration of the bridge at the entrance quarter-span cross beam section for various skew angles 


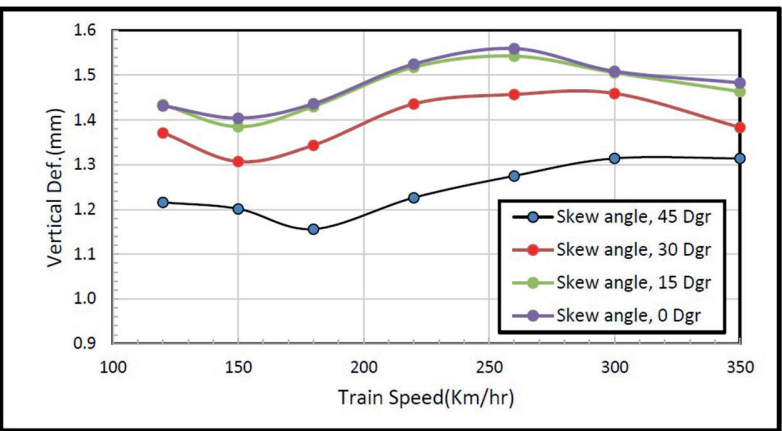

Two-way Passing

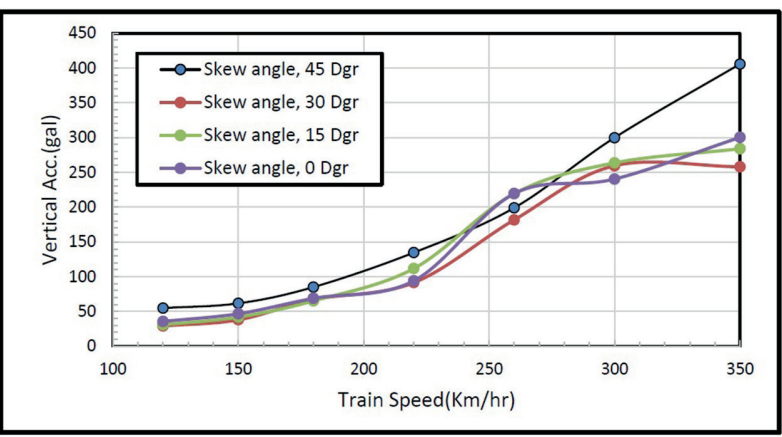

Two-way Passing

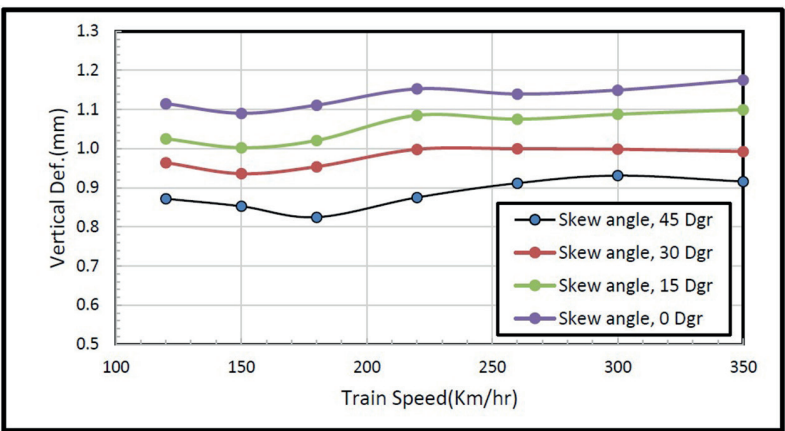

One-way Passing

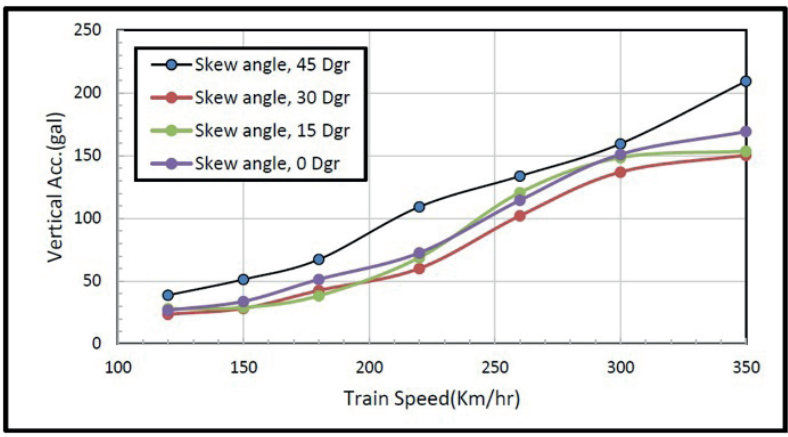

One-way Passing

Fig. 17 Deflection and acceleration of the bridge at the mid -span cross beam section for various skew angles

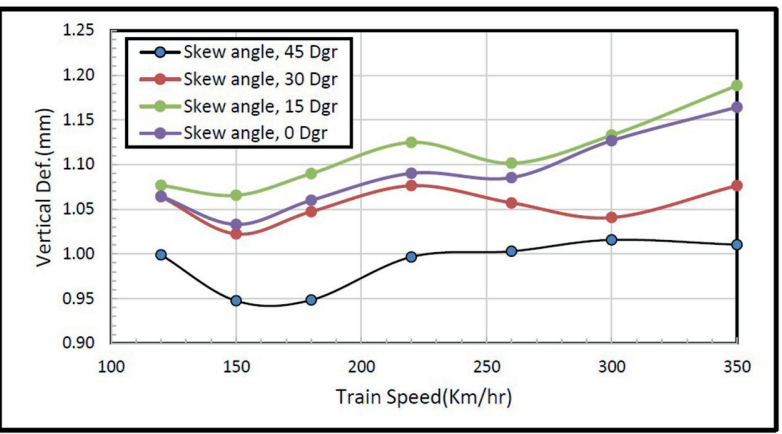

Two-way Passing

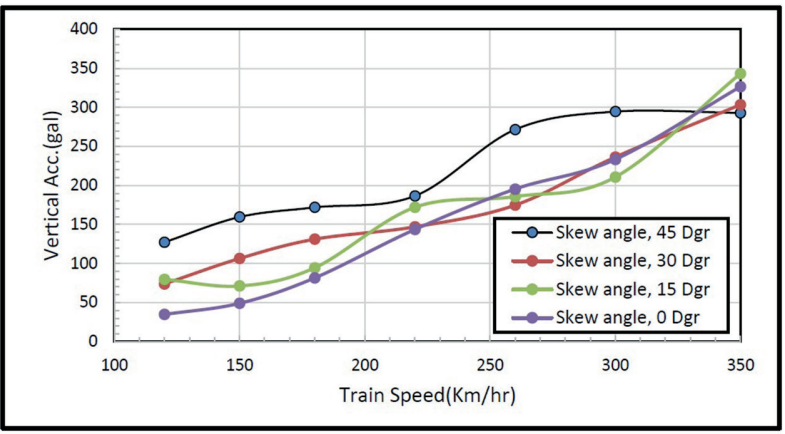

Two-way Passing

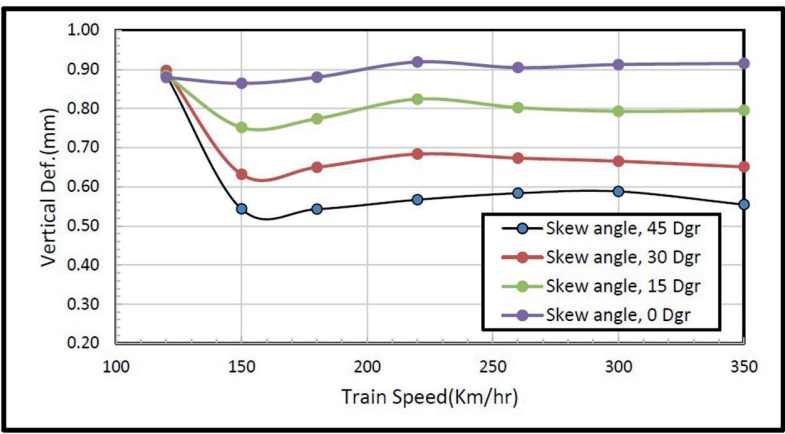

One-way Passing

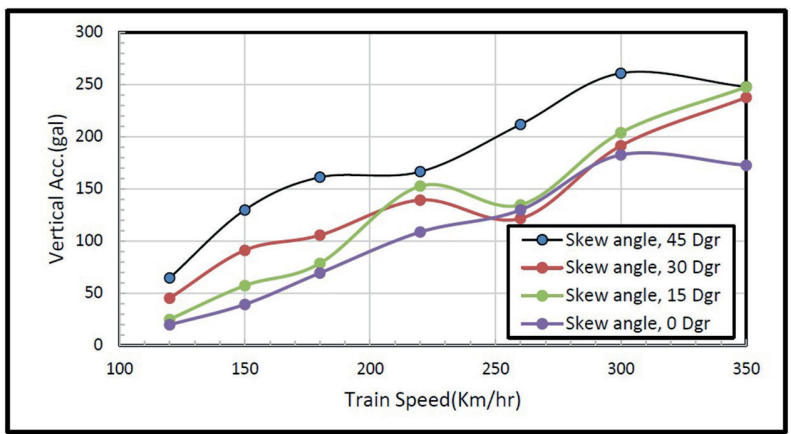

One-way Passing

Fig. 18 Deflection and acceleration of the bridge at the outlet quarter-span cross beam section for various skew angles 
According to Fig. 18, the maximum deflection of the cross beam section of the bridge's exit decreases for higher skew angles for both single- and double-sided crossings. However, the deflection of this section for the single-sided crossing scenario is almost always the same, regardless of skew degree. It is not the case for acceleration, however, and the $45^{\circ}$ skewed bridge has the highest acceleration values from among the studied bridges.

\section{Conclusions}

The aim of this paper was to study the response of highspeed skewed railway bridges carrying two tracks to the crossing of high-speed trains. Two scenarios, single- and double-train crossings, and four skew angles of $0,15,30$, and $45^{\circ}$ were considered. The finite element models of the bridge, trains, and their interaction were developed and calibrated based on field test results.

According to results, it is found that maximum deflection and acceleration values are recorded in different locations. Maximum deflection is recorded in the mid-span, while maximum acceleration occurs in the quarter span. In case of double train crossings, both maximum acceleration and deflection occur in the mid-span.

It is also concluded that the skew degree affects the modal shapes and natural frequencies of the bridge. For 15 and $30^{\circ}$ skewed bridges, the first three natural frequencies are similar to those of a straight bridge, yet for the $45^{\circ}$ skewed bridge, only the first mode shape is similar to that of the straight bridge. The first three natural frequencies of the $15^{\circ}$ skewed bridge and straight bridge are almost equal, yet for higher skew angles, the difference increases. In this regard, it may be stated that the response of a $15^{\circ}$ skewed bridge is similar to that of a straight bridge.

In longitudinal center-line of the bridge, higher skew degrees result in less deflection for both single- and double-sided train loading scenarios. The response of the $15^{\circ}$ skewed bridge is similar to that of a straight bridge in this case too. The alteration of modal frequencies of the skewed bridges affects the crossing speed at which the maximum deflection is recorded. Maximum displacement for a $15^{\circ}$ skew bridge occurs at the crossing speed of 260 $\mathrm{km} / \mathrm{h}$, whereas that of $30^{\circ}$ and $45^{\circ}$ skew bridges occur at the speeds of 300 to $350 \mathrm{~km} / \mathrm{h}$, respectively. Furthermore, acceleration values in single- and double-sided crossings vary significantly. In single-sided crossings, lateral twist mode shapes were excited due to the unsymmetrical loading of the bridge, whereas for double crossings, longitudinal and diagonal twist shapes are dominant. Acceleration values tend to increase for both scenarios; yet, the corresponding speed at which the maximum accelerations are observed different for various skew angles. For a straight bridge, maximum accelerations are observed at the speed of $260 \mathrm{~km} / \mathrm{h}$, while those of skewed bridges have a positive correlation with speed, meaning that they increase for higher crossing speeds.

The cross beam section at the entrance quarter-span of the bridge are not affected by skew angle for the single-sided loading scenario. On the other hand, for the double-sided loading scenario, deflection is reduced for higher skew angles. A positive correlation exists between skew angle and acceleration value, suggesting that the highest acceleration values are recorded for the bridge with a $45^{\circ}$ skew angle for both single- and double-sided loading scenarios.

In the cross beam section in the middle of the bridge, higher skew angles reduce the deflection in both singleand double-sided loading scenarios. The speed corresponding to maximum deflection observations is not constant for various skew angles. Results for a $15^{\circ}$ skew bridge are almost similar to those of a straight bridge, yet acceleration values are again correlated to skew angle, and the highest acceleration values are recorded for a $45^{\circ}$ skew bridge.

In the cross beam section of the quarter span of the bridge's exit, maximum deflection for both single- and double-sided loading scenarios are decreased with higher skew angles. Deflection values for the single-sided loading scenario are almost always constant for various skew angles at the speed of $120 \mathrm{~km} / \mathrm{h}$. Still, a positive correlation between crossing speed and acceleration values is observed in this section. The highest acceleration values are recorded for a $45^{\circ}$ skew bridge.

\section{Acknowledgments}

This research was supported by the Railway Engineering Department and Research and Technology Affairs of Iran University of Science and Technology. Authors wish to thank this generous support. 


\section{References}

[1] Jahangiri, M., Zakeri, J.-A. "Dynamic analysis of train-bridge system under one-way and two-way high-speed train passing", Structural Engineering and Mechanics, 64(1), pp. 33-44, 2017. https://doi.org/10.12989/sem.2017.64.1.033

[2] Yang, Y.-B., Yau, J.-D., Hsu, L.-C. "Vibration of simple beams due to trains moving at high speeds", Engineering Structures, 19(11), pp. 936-944, 1997.

https://doi.org/10.1016/S0141-0296(97)00001-1

[3] Delgado, R. M., dos Santos, S. M. "Modelling of railway bridge-vehicle interaction on high speed tracks", Computers and Structures, 63(3), pp. 511-523, 1997.

https://doi.org/10.1016/S0045-7949(96)00360-4

[4] Liu, K., De Roeck, G., Lombaert, G. "The effect of dynamic trainbridge interaction on the bridge response during a train passage", Journal of Sound and Vibration, 325(1-2), pp. 240-251, 2009. https://doi.org/10.1016/j.jsv.2009.03.021

[5] Rezvani, M. A., Vesali, F., Eghbali, A. "Dynamic response of railway bridges traversed simultaneously by opposing moving trains", Structural Engineering and Mechanics, 46(5), pp. 713-734, 2013. https://doi.org/10.12989/sem.2013.46.5.713

[6] Su, D., Fujinoa, Y., Nagayama, T., Hernandez Jr., J. Y., Seki, M. "Vibration of reinforced concrete viaducts under high-speed train passage: measurement and prediction including train-viaduct interaction", Structure and Infrastructure Engineering, 6(5), pp. 621-633, 2019 https://doi.org/10.1080/15732470903068888

[7] Meng, J., Ghasemi, H., Lui, E. M. "Analytical and experimental study of a skew bridge model", Engineering Structures, 26(8), pp. 1127-1142, 2004. https://doi.org/10.1016/j.engstruct.2004.03.013

[8] Xia, H., Zhang, N., Gao, R. "Experimental analysis of railway bridge under high-speed trains", Journal of Sound and Vibration, 282(1-2), pp. 517-528, 2005 https://doi.org/10.1016/S0022-460X(03)00202-5

[9] Ashebo, D. B, Chana, T. H. T., Yu, L. "Evaluation of dynamic loads on a skew box girder continuous bridge Part II: Parametric study and dynamic load factor", Engineering Structures, 29(6), pp. 1064 1073, 2007.

https://doi.org/10.1016/j.engstruct.2006.07.013

[10] Nguyen, D.-V., Kim, K.-D., Warnitchai, P. "Simulation procedure for vehicle-substructure dynamic interactions and wheel movements using linearized wheel-rail interfaces", Finite Elements in Analysis and Design, 45(5), pp. 341-456, 2009.

https://doi.org/10.1016/j.finel.2008.11.001

[11] Xia, C. Y., Lei, J. Q., Zhang, N., Xia, H., De Roeck, G. "Dynamic analysis of a coupled high-speed train and bridge system subjected to collision load", Journal of Sound and Vibration, 331(10), pp. 2334-2347, 2012. https://doi.org/10.1016/j.jsv.2011.12.024

[12] He, X. H., Sheng, X. W., Scanlon, A., Linzell, D. G., Yu, X. D. "Skewed concrete box girder bridge static and dynamic testing and analysis", Engineering Structures, 39, pp. 38-49, 2012.

https://doi.org/10.1016/j.engstruct.2012.01.016
[13] Adam, C., Salcher, P. "Dynamic effect of high-speed trains on simple bridge structures", Structural Engineering and Mechanics, 51(4), pp. 581-599, 2014.

https://doi.org/10.12989/sem.2014.51.4.581

[14] Deng, Y., Phares, B. M., Greimann, L., Shryack, G. L., Hoffman, J. J. "Behavior of curved and skewed bridges with integral abutments", Journal of Constructional Steel Research, 109, pp. 115-136, 2015. https://doi.org/10.1016/j.jcsr.2015.03.003

[15] Li, Z., Li, S., Lv, J., Li, H. "Condition assessment for high speed railway bridge based on train induced strain response", Journal of Structural Engineering and Mechanics, 54(2), pp. 199-219, 2015. https://doi.org/10.12989/sem.2015.54.2.199

[16] Ugarte, J., Carnerero, A., Millanes, F. "Dynamic behavior of pergola bridge deck of high speed railways", Structural Engineering and Mechanics, 61(1), pp. 91-103, 2017. https://doi.org/10.12989/sem.2017.61.1.091

[17] Gia, K. N., Goicolea, J. M. "Vibration analysis of short skew bridges due to railway traffic using analytical and simplified models", Procedia Engineering, 199, pp. 3039-3046, 2017. https://doi.org/10.1016/j.proeng.2017.09.407

[18] Bhaskar, A., Johnson, K. L., Wood, G. D., Woodhouse, J. "Wheelrail dynamics with closely conformal contact, Part 1: Dynamic modelling and stability analysis", Journal of Rail and Rapid Transit, 211(1), pp. 11-26, 1997. https://doi.org/10.1243/0954409971530860

[19] Lysmer, J., Kuhlemeyer R. L. "Finite Dynamic Model for Infinite Media", Journal of the Engineering Mechanics Division, 95(4), pp. 859-878, 1969. [online] Available at: http://cedb.asce.org/ CEDBsearch/record.jsp?dockey=0016353 [Accessed: 15 May 2019] 